\title{
DENT, Alexander Sebastian. River of tears: country music, memory and modernity in Brasil
}

João Miguel Sautchuk

\section{(2) OpenEdition}

1 Journals

Edição electrónica

URL: https://journals.openedition.org/aa/540

DOI: $10.4000 / a a .540$

ISSN: 2357-738X

Editora

Programa de Pós-Graduação em Antropologia Social (UnB)

\section{Edição impressa}

Data de publição: 31 dezembro 2013

Paginação: 283-286

ISSN: 0102-4302

\section{Refêrencia eletrónica}

João Miguel Sautchuk, «DENT, Alexander Sebastian. River of tears: country music, memory and modernity in Brasil», Anuário Antropológico [Online], v.38 n.2 | 2013, posto online no dia 01 fevereiro 2014, consultado o 07 dezembro 2022. URL: http://journals.openedition.org/aa/540 ; DOI: https:// doi.org/10.4000/aa.540

Este documento foi criado de forma automática no dia 28 abril 2021.

\section{(c)}

Creative Commons - Atribuição-NãoComercial-SemDerivações 4.0 Internacional - CC BY-NC-ND 4.0 https://creativecommons.org/licenses/by-nc-nd/4.0/ 


\title{
DENT, Alexander Sebastian. River of tears: country music, memory and modernity in Brasil
}

\author{
João Miguel Sautchuk
}

\section{REFERÊNCIA}

DENT, Alexander Sebastian. 2009. River of tears: country music, memory and modernity in Brasil. Durham: Duke University Press. 297 pp.

1 River of tears: country music, memory and modernity in Brasil, de Alexander Sebastian Dent (professor de antropologia na George Washington University, EUA), consiste numa análise etnográfica da música rural mediatizada das regiões Sudeste, Centro-Oeste e Sul do Brasil, que busca compreender a modernidade brasileira e como ela se configura a partir de uma relação contínua e dialética com o passado idealizado na representação da ruralidade. Este brasilianista denomina de "música rural" precisamente duas vertentes, ou gêneros, de canção popular amplamente conhecidas no Brasil como "música caipira" e "música sertaneja", tomando-as como facetas do mesmo fenômeno.

o tema geral do livro é a natureza paradoxal da modernidade brasileira, uma "modernidade em tom menor" (porque triste e emotiva) que olha constantemente para o universo rural como lugar de passado para construir sua representação da industrialização, do progresso, do crescimento urbano e da globalização. Nesse sentido, Dent concebe a "ruralidade brasileira" como uma ideologia e uma prática que valorizam um passado rural idealizado em detrimento de um presente urbano deteriorado. A investigação dessa ruralidade privilegia a análise das transformações na prática da música rural no Centro-Sul do Brasil a partir de meados da década de 1980, principalmente o crescimento no país das vendas de disco e da difusão pela mídia da música sertaneja (de pretensões modernizadoras), a consolidação de um circuito 
brasileiro de rodeios, as telenovelas de temática rural e um revival da música caipira (saudosista de um modo de vida em declínio).

O grande mérito do trabalho está em tecer esta interpretação sem limitar-se à análise de discurso das letras das canções e de textos acadêmicos, literários e midiáticos, conseguindo, para além disso, situar etnograficamente o caráter performativo desta representação moderna do universo rural. Entendendo que as práticas musicais podem ser vias de acesso para o estudo de dinâmicas capilares de reprodução social (como realizado por Anthony Seeger em Why Suyá Sing?, 1984) e das negociações e dos conflitos em torno de representações que uma sociedade constrói a seu próprio respeito (como analisado por Hermano Vianna em O Mistério do Samba, 1995), o autor desenvolve uma análise que transita entre estas duas ênfases, construindo um rico diálogo entre elas. Categorias abrangentes relativas a espaço, tempo, gênero, raça, classe social, nacionalidade e modernidade, elaboradas nas canções e nas performances musicais do rural veiculadas pelos meios de comunicação de massa, são analisadas em função da experiência de seus atores como elemento constitutivo das subjetividades na sociedade brasileira. Assim, a análise de um circuito da "cultura pública" busca ponto de apoio na solidez de uma detalhada etnografia das práticas (realizada em Campinas e outras cidades paulistas entre 1998 e 2009), buscando entender a integração de valores, instituições, atores e gêneros neste campo de produção cultural (:25).

Atento à bibliografia sobre a música caipira e sertaneja produzida por especialistas no assunto (Rosa Nepomuceno, Roberto Corrêa, Paulo Freire), cientistas sociais (José de Souza Martins, Antônio Cândido, Waldenir Caldas, Suzel Reily) e musicólogos (Martha de Ulhôa Carvalho), Dent desenvolve sua análise em oito capítulos equilibrados e bem alinhavados, encadeando o fluxo das ideias e dos argumentos de maneira que a cada capítulo se agrega a discussão. Há, é verdade, alguns erros de referência factual e de grafia de nomes de lugares, que não prejudicam a análise empreendida, sendo falha mais sentida a ausência de transcrições na língua original (isto é, em português) das letras das canções analisadas.

Dent aponta a dicotomia entre sertão e cidade como elemento central da modernidade brasileira. A idealização ou a estereotipia de um passado distante atrelado ao espaço igualmente distante do campo está no núcleo da própria concepção da modernidade que se apoia em um sistema de oposições análogas referentes a categorias de tempo, lugar, gênero, subjetividade, organização social, raça e classe social: cidade/sertão, moderno/tradicional, futuro/passado, masculino/feminino, racional (controlado)/ emocional (copioso), parentesco/anonimato, diferença e miscigenação entre brancos/ negros/caboclo, elite/trabalhador etc.

6 Para entender o desenvolvimento da performatividade do rural na sociedade brasileira no decorrer do século XX, Dent toma como um mito original a composição "Tristeza do Jeca", de 1918, na qual um protagonista caipira lamenta a impossibilidade de retornar a seu local de origem (lugar este perdido em um passado inacessível). 0 tema deste mito, desdobrado desde então em muitas variações, fornece um enquadramento para as transformações na relação entre campo e cidade, situando o primeiro polo (o passado rural idílico) como crítica ao segundo (o tempo urbano fragmentado). No presente (fragmentado), o protagonista [eu lírico da canção] está geográfica e cronologicamente apartado de um momento em que ele se sentia inteiro. Este lamento pela impossibilidade de retorno ao lugar, ao tempo ou à relação amorosa que teve fim é 
recorrente na canção rural do início do século XX, com um acento sobre a última variação (a paixão não correspondida) a partir da década de 1980 (:29).

O elemento aglutinador do sistema mítico das canções rurais é a representação da emotividade (efetivada no próprio ato de cantar, tido como expressão sentimental) que perpassa este gênero de canção - seja pela experiência da migração (a saudade do sertão e o desajustamento na cidade), tema recorrente na música caipira, seja no sofrimento pelo fim do caso amoroso, predominante na música sertaneja que se consolida na década de 1980. Em ambas as vertentes, a emoção é oposta ao controle, ao poder e à racionalidade. Recorrendo ao conceito de intimidade cultural de Michael Herzfeld, Dent mostra que esta intimidade construída num plano coletivo serve, no contexto de neoliberalismo, tanto à produção das referências de localidade e tradicionalismo quanto às de cosmopolitismo e modernidade.

Para tal, Dent entende os gêneros musicais, para muito além de regularidades estéticas, como campos de possibilidades em que as experiências de músicos e ouvintes se desenrolam fornecendo modos de pensar e posicionamentos no campo de produção cultural. O gênero é pensado aí como um sistema de práticas compartilhadas, consistindo tanto em um conjunto de disposições inconscientes quanto em formas de atividades ideologicamente orientadas. E, como as categorias de qualquer sistema de classificação, são definidos por contrastes entre si (:109, 113-114).

9 Um elemento fundamental na música rural é o canto em dupla, formação tradicional na música caipira e mantida na música sertaneja, que aglutina uma experiência do valor da consanguinidade, ou seja, afirma o parentesco como feixe de relações fundamentais (porque inescapáveis) sobre quaisquer outras - entre as duplas mais célebres da música rural, as mais duráveis foram e são formadas por irmãos. Uma vez que a migração do meio rural para o urbano sugere transformações individuais de grande magnitude, a performatividade de duas vozes cantadas e ouvidas como uma só fornece uma mediação para os vínculos entre espaço, tempo e pessoa, bem como um enquadramento para as rupturas da vida moderna por meio da remissão à consanguinidade enquanto valor social $(: 57,64)$. A atuação da dupla impõe uma dualidade entre igualitarismo (o canto a duas vozes, em intervalo de terça, as quais devem soar como se fossem uma só, o figurino padronizado) e hierarquia (entre primeira e segunda vozes, entre quem compõe e quem apenas canta, entre quem assume o protagonismo nas apresentações e quem fica em segundo plano).

10 Nas apresentações de música caipira, a estética musical e as temáticas idílicas são conjugadas ao uso do sotaque e do linguajar caipiras, a tradições gastronômicas e à simplicidade de "produção" dos shows (palco, luzes, o acompanhamento instrumental, que geralmente se resume ao duo de viola e violão tocados pelos próprios cantores) no sentido de uma experiência de afirmação de valores do universo camponês e de contraposição ao cosmopolitismo moderno. Já na música sertaneja, a grandiloquência dos contextos de performances (palcos gigantescos com farta parafernália de som e luzes, dançarinas, bandas numa configuração comum à música pop, plateias massivas) confluem com o uso de um linguajar urbano e "correto" e com as temáticas amorosas para a experiência de um cosmopolitismo que enfatiza a emotividade como elemento que perpassa a vida social (por exemplo, com a ritualização da perda do poder masculino diante do amor). Assim, da mesma forma que a localidade só pode ser afirmada em relação à concepção de uma totalidade mais ampla, o cosmopolitismo será 
sempre uma tentativa de lançar-se na modernidade, mas inevitavelmente sob a clave de um local peculiar.

11 Vale ressaltar que, após o período coberto pela pesquisa em pauta, consolidou-se uma nova vertente da música rural, denominada "sertanejo universitário". Num breve levantamento, nota-se que esta vertente apresenta mudanças significativas. A temática do sentimentalismo melancólico perde sua centralidade em favor de uma estética da festa, da conquista sexual e da felicidade na união amorosa. Concomitantemente, para estes novos cantores e compositores, a dupla tanto deixa de ser uma forma necessária quanto pode representar relações outras que não a consanguinidade - a afinidade, por exemplo. Assim, vários de seus expoentes são cantores que seguem carreira solo, ao mesmo tempo em que há também uma célebre dupla formada por um rapaz e uma moça - marido e mulher que fazem desta relação um capital artístico. Esta transformação de caráter sistêmico da canção sertaneja como ideologia e prática corrobora a interpretação de Dent e aponta um norte para novas análises etnográficas nesse campo. Tais análises não podem ignorar a relação entre gênero e performance musicais, bem como seu poder performativo sobre as experiências sociais, no que se refere às concepções e às relações de gênero, classe, em função de novas nuances da oposição rural/urbano na modernidade brasileira.

\section{AUTORES}

\section{JOÃO MIGUEL SAUTCHUK}

UFPI 